\title{
BLACK GUILLEMOTS IN A MELTING ARCTIC: RESPONDING TO SHIFTS IN PREY, COMPETITORS, AND PREDATORS
}

\author{
GEORGE Divoky \\ Friends of Cooper Island, $65232^{\text {nd }}$ Ave. E, Seattle, WA 98112, USA. \\ E-mail: divoky@cooperisland.org
}

\begin{abstract}
Arctic species closely associated with snow and ice habitats will be among the first to be affected by rising atmospheric temperatures. The Black Guillemot (Cepphus grylle mandti) is a high-arctic seabird nesting in ground-level cavities in northern Alaska and feeding in and next to the arctic pack ice. Since 1975 the species has been studied annually at a colony in northern Alaska. Observations of breeding phenology and success found that temperature-induced changes in snow and sea ice habitats recently allowed the species to colonize the region but now are preventing successful reproduction.
\end{abstract}

Black Guillemots did not breed in northern Alaska until the late 1960s, when warming temperatures allowed access to nest cavities for the 80 days needed for successful reproduction. During the 1970s and 1980s, guillemots thrived as summer length continued to increase and arctic pack ice remained within the $40 \mathrm{~km}$ foraging range of breeding colonies, allowing access to adult Arctic Cod (Arctogadus glacialis) associated with sea ice. Continued increases in temperature and resulting reductions in summer pack extent in the late $20^{\text {th }}$ and early $21^{\text {st }}$ Century resulted in decreased nesting success by modifying the distribution and abundance of guillemot prey, competitors, and predators. As availability of adult Arctic Cod decreased with summer ice extent, parents turned to smaller cod and lower-quality benthic prey to provision young, leading to brood reduction and lower fledging weights. Decreasing ice also allowed the Horned Puffin (Fratercula corniculata), a subarctic seabird, to colonize the region and compete with guillemots for nest cavities. Prospecting puffins now regularly kill up to half of the guillemot nestlings. Lastly, Polar Bears (Ursus maritimus), abandoning the summer sea ice as it retreats off the continental shelf, swim to the island where they eat guillemot eggs and nestlings, causing almost complete nesting failures in the past three years. Breeding success of guillemots is currently insufficient to maintain a breeding population in the region.

These observations of rapid changes in an apex predator supported by the cryopelagic ecosystem demonstrate some of the biological effects of the well-documented reductions in summer extent of the arctic pack ice. Similar or related effects are likely influencing ice-associated vertebrate populations throughout the Arctic Basin and will reach a critical threshold with the predicted disappearance of summer ice later in this century. Transcribed from oral presentation given on $1 \mathrm{Feb}-$ ruary 2011. 
DivoKy, G. 2011. Black Guillemots in a melting Arctic: Responding to shifts in prey, competitors, and predators. Transcription, pages 125-130 in R. T. Watson, T. J. Cade, M. Fuller, G. Hunt, and E. Potapov (Eds.). Gyrfalcons and Ptarmigan in a Changing World, Volume I. The Peregrine Fund, Boise, Idaho, USA. http://dx.doi.org/10.4080/gpcw.2011.0112

Key words: Arctic Cod, Sculpin, fish, Horned Puffin, predators, prey, Polar Bear, sea birds, climate warming, sea ice.

BLACK GUILLEMOTS (Cepphus grylle mandti) share the high Arctic with Gyrfalcons (Falco rusticolus) and ptarmigan, and may occasionally become prey for Gyrfalcons. I have been studying Black Guillemots for the past 40 years in the northernmost part of the Bering Sea arc, where the Arctic Basin comes into contact at the Bering Strait. I was asked to present on this species because there may be insights from my work that can be applied to understanding and predicting the effects of climate change on the predator-prey relationship between Gyrfalcons and ptarmigan.

The Black Guillemot is a species that has critical life history stages constrained by and advanced by the presence of snow and ice. It was recognized in the mid-1990s that species with critical life history stages either restricted by or dependent on snow and ice habitats will be among the first to be affected by increases in atmospheric temperature because snow and ice habitats respond directly to climate change, unlike forest or other habitats that respond progressively to warming trends. A shift of a few degrees in mean temperature can change everything in a snow and ice habitat as it melts. If you need to walk on the ice, as do Polar Bears (Ursus maritimus), you are in trouble when it becomes liquid. If you need to be under the snow, like lemmings, you are in trouble when there isn't enough snow cover to protect you from predation. This is an important issue to consider for arctic species that have adapted to living in or on snow and ice. Subarctic species may benefit from a warming climate to the extent that they can move north as change occurs.
The Black Guillemot is a cavity nesting sea bird. It has very high plasticity in nest site selection. Although it is typically found on rock cliffs, rocky shorelines, and tallus, it will breed just about anywhere suitable cover can be found. It is semi-colonial, so whereas most alcids take around 1,000 conspecifics to raise their young, guillemots can do it with two birds. That means they are able to move into new areas rather quickly, and that is one of the things I have seen in arctic Alaska. They typically forage in the near-shore during the breeding season. They do not feed far off-shore like most of the other alcids and they use nearshore food resources to the point where they can actually raise two young.

This subspecies of Black Guillemot, C. $g$. mandti, which was considered its own species up until 1940, was trapped north of the Bering land bridge during the last glacial maximum, lost all its migratory inclination because sea birds don't fly over land, and was subject to a major genetic bottleneck about 21,000 years ago. They had to survive in the Arctic, dealing with arctic resources and the Arctic as it existed, foraging in sea ice all year. You can get an idea of what the Arctic must have been like 21,000 years ago by looking at what the sea ice is like in winter now, with very small areas of open water where there are cracks in the ice that form because the ice shifts. It's well below freezing, so the ice starts forming again right away after it cracks, and guillemots had to find these cracks, feed on something under the ice, which was Arctic Cod (Arctogadus glacialis), as quickly as they could. Then as the sea froze, they had to get up in the air again and find the next crack that was then 
opening up. If cracks opened up, they died, which was certainly why there was a major genetic bottleneck 21,000 years ago. The species is a true arctic species, it occupies the mainland that is snow covered for eight to nine months of the year; it is intimately associated with ice and snow throughout its annual cycle. Unlike other species, like Arctic Loons (Gavia arctica) and shorebirds that people call arctic sea birds because they spend three months in the Arctic, guillemots are married to the Arctic while most of the species you see in the tundra are just dating it for a few months.

There are not many prey resources in the Arctic Basin because the water is highly stratified, there's no upwelling, and all of the food production is taking place right under the ice. Guillemots 21,000 years ago had to key in on what was immediately under the ice so they keyed in on Arctic Cod. We know what they feed on because of observations that we started in 1975 of birds coming back to feed their young, and because they carry their fish back to the nest in their bill we can see exactly what they are eating, unlike other birds that regurgitate their prey. With careful observation we can see what they are feeding on a daily and annual basis. We also know from the isotopes in their feathers that grow during the winter and spring that they are feeding on Arctic Cod throughout the winter. So, guillemots are feeding on Arctic Cod for 12 months a year, as are other sea ice dependent predators like seals which, in turn, feed Polar Bears. Arctic Cod are running the system under the ice in a similar way that lemmings run some systems on the tundra. It's a very high fat fish; it is found at $-1.8^{\circ} \mathrm{C}\left(28^{\circ} \mathrm{F}\right)$ under the ice, so it has to be fat to be moving around there. The under-surface of ice is not unlike an inverted coral reef where you have invertebrates feeding on phytoplankton and diatoms coming out of the ice and then Arctic Cod feeding on them. So it is a very important system that is operating under the ice and Black Guillemots, because they got stranded in this ecosystem, had to adapt to feeding off the system.

\section{Climate Change Effects ON BLACK GUILLEMOTS}

Since beginning observations on guillemots in the early 1970s, I have observed a change in their habitat that started when the summers got long enough to allow them to breed in northern Alaska for the first time, which first happened only 40 years ago. As it got warmer and warmer, this window of opportunity for them to breed has closed again, so that now in 2010, northern Alaska is a place where guillemots can not breed successfully even though they could only breed there successfully for the first time in 1968. I have seen and documented this rate of change by spending three months a year for 40 years on the island collecting a lot of data.

Global surface temperature trends for the two decades before I started the study, from 1951 to 1969 , show that much of the globe's surface temperature decreased in that period with relatively slight warming in just a few regions.

I started the study in the early 1970 s, and over the next three decades the global surface temperature trended up, with a $2-4{ }^{\circ} \mathrm{C}$ shift in northern Alaska. Because this area is dominated by snow and ice habitats, this shift will cause melting to occur especially in areas that straddle the $0^{\circ} \mathrm{C}\left(32^{\circ} \mathrm{F}\right)$ isotherm, as Barrow Alaska does on an annual basis during the summer.

Guillemots were always known to breed on two islands in the Russian Chukchi Sea, Herald and Rangel islands, and in the southern Alaska Chukchi Sea but they were not found breeding in Barrow until 1968, when they were found breeding under a wall board. I found my colony in 1972 and Dave Mossop and others found a colony on Hershel Island in the mid-1970s. All of these were in man-made nest sites which was interesting at the time because these were the first breeding records; although guillemots had been there for quite some time, local people had been using them for food, and ornithologists from the mid-1800s had been collecting 
them. This was not surprising since the northern Alaska shoreline has no suitable breeding habitat such as rock cliffs, so as a result, the only sort of nest sites that you might get are under drift $\log$ s that wash up on shore. There may have been nest sites there but no one found them there until the late 1960s and early 1970s. I went to Cooper Island in the early 1970s and found a colony that was breeding in debris that had been left there by the Navy. It was a good place to study them because I could easily access adults, eggs and chicks, and I could create additional nest sites by piling debris to create a cover for the birds to nest under. The colony went from 10 pairs in 1972 to 200 pairs in the late 1980s just by creating nest sites, and thereby increased my sample size. It became the largest and least attractive Black Guillemot colony and seabird colony in the state of Alaska. But it also provided easy access and a unique study opportunity.

We didn't detect anything going on with climate change until we went up there early one year to find the island was still covered with snow. Up until early June, the birds arrive and immediately settle into the nest sites that still have snow in them, and then the female lays eggs 12 to 14 days later. Over the time period I was doing the study, NOAA was gathering snow-melt data and we found a very good correlation between the snow-melt and the day of the first egg in the colony. It showed that the female can't form an egg until she has access to the cavity, and that both the date of laying and the date of melt were getting earlier as the climate warmed.

The time period required for breeding by guillemots is about 80 days ( 14 days for the female to form the eggs and three days to finish laying the clutch, 28-31 days for incubation, and the chick is in the nest for 35 days while it undergoes a ten-fold increase in its weight). Typically the length of the summer up there is 80 days. In 1988, it snowed in late August, earlier than the usual 80-day summer period, and trapped nestlings in the nest while adults waited outside with food. I plotted the length of the summer (days of snow-free ground) and found that 1988 did have a shorter than 80-day summer. I found that until the mid-1960s, it was common to have summers of less than 80 days, and it was also at that time, as summers began regularly to exceed the minimum 80-day breeding period, that the first breeding by guillemots occurred in Barrow.

Today, summer is now one month longer than when I started the study 40 years ago. This gives guillemots plenty of time to breed, but there are now some major negative implications as well. Initially, at least, climate warming helped guillemots by opening up the northern Alaska area to breeding over a much broader area than had previously been available.

There were a million Horned Puffins (Fratercula corniculata) breeding in the Bering Sea and Gulf of Alaska as far north as Cape Lisbon in the southern Chukchi Sea. As the climate warmed they moved up in northern Alaska to Cooper Island, and by 1986 had started breeding there. Unfortunately, they use the same nest cavities as Black Guillemots, and they are almost twice the weight (Black Guillemots are $400 \mathrm{~g}$, Horned Puffins are $700 \mathrm{~g}$ ), so they breed wherever they want if they find a cavity. Breeding puffins are not very abundant, but there are lots of non-breeders prospecting nest sites, and when they do that they kill guillemot chicks. In the summer of 2009, we had 183 Black Guillemot chicks hatched, of which 81 were killed by Horned Puffins. So this is an example of a sub-arctic species moving into the Arctic because the ice is melting, and having an impact on a true Arctic species.

In addition, the feeding range of the Black Guillemots on Cooper Island used to have lots of sea ice within range, with lots of Arctic Cod directly under it. Today, there is no sea ice in the guillemots' feeding range by late August and early September, so they can no longer feed on Arctic Cod. Instead they are turning to 
things like Four-horned Sculpin (Triglopsis quadricornis) and other near-shore bottom fish that are not as abundant and not as high quality.

The result is that after the guillemot breeding colony grew in size through the 1970 s and 1980 s, because more nest sites were available and the snow cover was gone for longer periods, the colony declined in the 1990s because the sea ice had retreated far off-shore during the prime time of the breeding season, around the $10^{\text {th }}$ of August. Guillemot parents most likely key-in visually to the presence of ice because they know that they can find Arctic Cod under it; and when no ice is present, they do not know what they can catch. To understand the impact of retreating sea ice, for comparison, in 2006 ice was close to shore and Arctic Cod made up almost all the guillemots' diet. Then in 2007, the ice retreated and Arctic Cod in the diet declined to just 20 percent. As a result, chick growth rates and fledging weights decreased and brood reduction occurred. Today, brood reduction occurs in virtually every nest every year.

Continued warming is changing the ocean offshore. As soon as the ice started to pull north of the shelf break, Polar Bears had to go somewhere, so they came to Cooper Island. Prior to 2002, they were rare on the island. Today they are now a common occurrence from late July through August in increasing numbers and residence time, and contribute to increased guillemot chick mortality. In 2009, 90 of 183 guillemot chicks were killed by Polar Bears and 81 guillemot chicks were killed by Horned Puffins. Only one guillemot chick fledged, as the remaining 11 chicks were killed by other causes. So, the sub-arctic Horned Puffin that spread north, and the arctic Polar Bear that was forced south, now are causing increased predation and reduced productivity to the arctic Black Guillemot which, for the first 15 years of my study, did very well and benefitted from the warming climate.
From 1975 to 1990 , Black Guillemots had roughly 50 percent breeding success with 0.5 chicks fledged per nest, with enough production to maintain the colony. But breeding success has steadily declined, and from 2007 to 2010 , only 0.03 young fledged per nest, which is not enough to sustain the colony.

In the coming years, I am hoping to see whether and how the species adapts to the melting Arctic. We have all the birds banded and some of them are 29 years old. I will be able to see which individuals can find fish offshore and whether they will be able to adapt their foraging strategy to the new conditions. I am putting out bear-proof plastic cases to replace the 150 guillemot nest sites that are currently active to keep the "canary in the coal mine" alive to study a bit longer, because this is the only colony up there monitoring change in the Arctic, and it's the only colony that has 40 years of data prior to this major melt. There are also concerns about off-shore drilling, commercial fishing, and other things there, so if I can keep looking at what guillemots are bringing to their young or what their breeding success is without having Polar Bears eat them, then I will be able to keep a study going and find out something rather interesting.

\section{Conclusion}

During my research lifetime of 40 years I have observed the climate warm, and other conditions change from a time when guillemots could barely breed because it was too cold, to a period when it was suitable for breeding, neither too cold nor too hot for four decades, to now, when the species can only survive by breeding in bear-proof nest boxes. This is an ongoing study with results reported from the field on my website cooperisland.org. 
- DivokY - 